TITLE:

\title{
Dynamic analysis of earth dam damaged by the 2011 off the Pacific Coast of Tohoku Earthquake
}

\section{AUTHOR(S):}

Charatpangoon, Bhuddarak; Kiyono, Junji; Furukawa, Aiko; Hansapinyo, Chayanon

\section{CITATION:}

Charatpangoon, Bhuddarak ... [et al]. Dynamic analysis of earth dam damaged by the 2011 Off the Pacific Coast of Tohoku Earthquake. Soil Dynamics and Earthquake Engineering 2014, 64: 50-62

\section{ISSUE DATE:}

2014-09

URL:

http://hdl.handle.net/2433/188946

\section{RIGHT:}

(C) 2014 Elsevier Ltd.; This is not the published version. Please cite only the published version.; この論文は出版社版でありません。引用の際に は出版社版をご確認ご利用ください。 


\title{
Dynamic Analysis of Earth Dam Damaged by the 2011 Off the Pacific Coast of Tohoku Earthquake
}

\author{
Bhuddarak Charatpangoon $^{\text {a,* }}$, Junji Kiyono ${ }^{b}$, Aiko Furukawa ${ }^{b}$ \\ and Chayanon Hansapinyo
}

\begin{abstract}
${ }^{a}$ Department of Urban Management, Kyoto University, Kyoto 615-8530, Japan
${ }^{b}$ Graduate School of Global Environmental Studies, Kyoto University, Kyoto 615-8530, Japan

${ }^{c}$ Department of Civil Engineering, Chiang Mai University, Chiang Mai 50200, Thailand

"Corresponding author. Tel.: +8175-383-3252. Fax: +8175-383-3253.

E-mail addresses: bhuddarak@hotmail.com (B. Charatpangoon),

kiyono.junji.5x@kyoto-u.ac.jp (J. Kiyono), furukawa.aiko.3w@kyoto-u.ac.jp (A. Furukawa), chayanon@eng.cmu.ac.th (C. Hansapinyo).
\end{abstract}

Submitted to

Soil Dynamics and Earthquake Engineering

August, 2013 


\section{Highlights}

- Microtremor tests show fine agreement with modal analysis of the failed dam

- Laboratory tests provide data for investigating possible dam failure mechanisms

- Large shear strains and tension cracks might reveal the cause of sliding failure

- Sliding patterns yield fine agreement with evidence gathered from field observation

- Results show that loss of freeboard is induced when using the observed motion 


\begin{abstract}
This study examines possible failure mechanisms and dynamic behavior of the Fujinuma dam, which failed following the 2011 Off the Pacific Coast of Tohoku Earthquake. The study comprises two parts: an investigation through field and laboratory experiments, and a numerical simulation of the dam. Field measurements and laboratory experiments were conducted to acquire necessary information. Microtremor observations of the surviving portion of the failed dam were performed to extract data on its dynamic characteristics. Triaxial and other laboratory tests provided information required for the analysis. For the seismic analysis, a coupled solid-fluid finite element method was applied and observed and simulated motions of the 2011 Tohoku Earthquake used as input. Mechanical behavior of the dam material was described using the Mohr-Coulomb failure criterion. Frequency and dynamic analyses were performed and dam behavior and possible failure phenomena presented. Furthermore, a comparison between the simulation results and existing facts is discussed.
\end{abstract}

Keywords: Earth dam, earthquake, finite element, dynamic, Fujinuma dam. 


\section{Introduction}

Damage and loss of life caused by earthquakes are immense. This is magnified when accompanied by the collapse of essential infrastructure, such as a dam or a power plant, which has the potential of destroying entire cities. The water and power supplied by dams are essential for the survival of a community, not to mention the other benefits they bring, such as tourism and flood control. However, when a dam fails, the destruction is often deadly, causing irreparable damage to the land, the people, and to the economy.

Following the devastating earthquake in Japan on 11 March 2011, seven dams were damaged and the Fujinuma dam collapsed owing to the force generated by the 9.0-magnitude earthquake, known as the 2011 Off the Pacific Coast of Tohoku Earthquake (hereafter, the 2011 Tohoku earthquake). The Fujinuma dam was constructed to serve as a water supply for irrigation purposes. The dam was located on a tributary of the Abukuma River, near Sukagawa in Fukushima prefecture, Japan. It failed following the 2011 Tohoku earthquake (Fig. 1). The failure caused a flood that washed away 19 houses and damaged others, disabled a bridge, and blocked roads with debris. Seven bodies were discovered after searches began at dawn and one person was declared missing.

Generally, earth dams are the most common type of dam because of their cost and the convenient supply of raw materials. A number of earth dams exist throughout Japan for irrigation, flood mitigation, and hydroelectric power generation purposes. As Japan lies in one of the world's most seismically active areas, the main issue in dam management and construction is seismic safety. Therefore, to assure dam safety, proper evaluation of such dams is crucial. Accordingly, the failure of the Fujinuma dam can be regarded as a fruitful resource from which to gain insight into dam failure mechanisms and to acquire useful information relating to dam safety.

Fig. 1. (a) Location of the Fujinuma dam (@2013 Google. Map data. ( Google. ZENRIN). (b) Sukagawa and the dam site (Map data @2013 AutoNavi. Google. SK planet. ZENRIN). (c) Fujinuma dam.

In the computation of soil structures, the coupling behavior between the solid matrix and pore water is crucial. Biot [1,2] first developed a linear theory of poroelasticity and subsequently, many researchers in this field have established numerous solid-fluid coupling formulations based on different assumptions. Each technique has its own strengths in solving different problems. Among them, owing to its simplicity, the u-p formulation has become well known and applied widely in the field of geotechnics. Finite element (FE) codes for porous media have been developed continuously [3-7]. Recently, as advanced computational techniques in geotechnics have been introduced, it has become beneficial for researchers [8-15] to analyze seismic behavior of dams by using those techniques. Consequently, much research work has been conducted in the area of seismic safety on existing earth dams.

Soralump and Tansupo [16] conducted a dynamic response analysis of the Srinagarind dam by using 213 records of 35 earthquake events and the equivalent linear method for the nonlinear behavior of dam materials. Similarly, Fallah and Wieland [17] conducted an evaluation of earthquake safety of the Koman concrete-faced rock-fill dam in Albania, by using a two-dimensional FE model of the maximum cross section. Their study was undertaken using the equivalent linear method. The dam was checked for the safety evaluation earthquake with a peak ground acceleration of the horizontal 
component of $0.45 \mathrm{~g}$. Spectrum-compatible artificially generated accelerograms were used based on a site-specific seismic hazard analysis. All of these methods mentioned above have been applied to evaluate the safety of earth dams. The importance of such research is not only to examine the behavior of a dam or the level of damage it can sustain, but also to preserve it against future earthquakes.

Although dam failures are rare, studies have been conducted based on such events to understand the causes of those failures. One example is the failure of the Teton dam, an earthen dam located in Idaho, in the United States. It was $93 \mathrm{~m}$ high and had a capacity of 355 million $\mathrm{m}^{3}$. The dam failed on 5 June 1976, as it was being filled for the first time, owing to internal erosion known as "piping". The failure caused a huge flood that damaged the city downstream, which cost a total of about US\$2 billion $[18,19]$. The Lower San Fernando dam, which was a 40-m-high hydraulic-fill earth dam located in San Fernando, California, failed on 9 February 1971, as the San Fernando earthquake struck southern California. This seismic shaking triggered liquefaction of the hydraulic-fill within the upstream slope of the dam. During the earthquake, sliding was induced with a loss of strength in the liquefied soils, which led to failure causing significant damage downstream [20]. In Japan, the Aratozawa dam is a rock-fill impervious-core dam with the height of $74.4 \mathrm{~m}$, located in Kurihara, Miyagi prefecture. The Iwate-Miyagi Nairiku earthquake in 2008 caused huge landslides to occur on the left bank of the reservoir from the dam. This caused settlement of the core zone by about $20 \mathrm{~cm}$. There was no evidence of severe damage to the dam structure, but it was taken out of operation because of safety concerns [21].

Following the Fujinuma dam failure, Harder et al. [22] visited the site just a few weeks after the event. The principal purpose of the visit was to observe and document the failure of the main dam and the upstream slide in the auxiliary dam. Discussions on the failure mechanism and recommendations on future works were presented by the authors. In addition, Ono et al. [23] stated that the failure of the Fujinuma dam was only the second complete failure of such a dam in Japan's history. From official records, there are about 210,000 reservoirs in Japan, of which at least 20,000 are vulnerable to future earthquakes. Therefore, the contribution of this report is to raise awareness for reducing the potential of dam failures in future catastrophic events. Tanaka et al. [24] studied the failure of the Fujinuma dam; thus, comment and discussions on the cause of the dam failure have already been presented.

This study aims to gain insight into the behavior of the Fujinuma dam during the time of the earthquake by using the FE method. Both the observed motion and the simulated motion are used to determine the response of the dam during the excitation. The soil behavior of the dam materials is described by using the Mohr-Coulomb soil model available in the Plaxis FE code [25]. Dynamic analyses of the model are conducted, and the overall dam behaviors presented. Discussions and comparisons between the simulation results and existing facts are expressed.

\section{Site description and input motions}

\subsection{Fujinuma dam}

The Fujinuma dam was an earth-fill embankment dam near Sukagawa, Fukushima prefecture, Japan. It was established on the Ebana River, a tributary of the Abukuma River, $16 \mathrm{~km}$ west of the city office of Sukagawa $\left(37^{\circ} 18^{\prime} 07^{\prime \prime} \mathrm{N}, 140^{\circ} 11^{\prime} 41^{\prime \prime} \mathrm{E}\right)$. The dam construction began in 1937 and it was completed in 1949 after construction was halted during World War II. The primary purpose of the dam was 
water supply for irrigation. The cross section of the main dam and its layout are shown in Figs. 2 and 3. The dam was an embankment type, $18.5 \mathrm{~m}$ high and $133 \mathrm{~m}$ long with a structural volume of 99,000 $\mathrm{m}^{3}$ and a crest width of $6 \mathrm{~m}$. On the upstream face, the concrete frames and panels were installed in order to protect the dam from the erosion. However, there are gaps between these panels so these panels were not served as the impervious layer and still penetrable. In addition, there was an auxiliary dam with a height of about $6 \mathrm{~m}$ and a length of approximately $60 \mathrm{~m}$. The dam was at the head of an $8.8-\mathrm{km}^{2}$ drainage area giving a reservoir capacity of $1,504,000 \mathrm{~m}^{3}$ [26].

Fig. 2. Typical cross section of the main dam.

Fig. 3. Main dam layout.

\subsection{Ground motions}

The 2011 Tohoku earthquake, or the so-called Great East Japan Earthquake, was a magnitude 9.0 $(\mathrm{Mw})$ undersea megathrust earthquake off the Pacific coast of Japan, which occurred on 11 March 2011. The epicenter was about $70 \mathrm{~km}$ east of the Oshika Peninsula, in Miyagi prefecture, at a depth of approximately $32 \mathrm{~km}$ [27]. It was one of the most powerful earthquakes in the world since the establishment of the modern recording system. The ground motion record obtained from Station FKS017, Sukagawa, Fukushima prefecture, Japan, was provided by the Kyoshin network and operated by the National Research Institute for Earth Science and Disaster Prevention [28]. These data were observed about $15 \mathrm{~km}$ away from the dam site. Furthermore, Hata et al. [29] also investigated the simulated ground motion at the dam site. They estimated the ground motion for the dam site by microtremor observation by using the site effect substitution method. These motions were used in the dynamic analysis of the dam. The peak ground acceleration $a_{\max }$ was 4.198 and $4.25 \mathrm{~m} / \mathrm{s}^{2}$ for the observed and simulated motions, respectively (Fig. 4a and b). The spectra of both motions are shown in Fig. 4c and d. The predominant period of both motions was 2.71 and $2.96 \mathrm{~Hz}$, respectively. The smoothed spectra of both motions were also introduced by applying a 50-period moving average (50 per.Mov.Avg.) as shown in Fig. $4 \mathrm{c}$ and d. The predominant period of both motions was therefore 2.73 and $4.40 \mathrm{~Hz}$, respectively. In addition, to verify the effects of the phase of ground motion, the opposite wave forms were also used as additional input motions for this study.

Fig. 4. Input motions. (a) Observed motion at FKS017 $15 \mathrm{~km}$ from the dam site [28]. (b) Simulated motion at the dam site [29]. (c) Spectrum of observed motion. (d) Spectrum of simulated motion.

\subsection{Dam materials and their properties}

The material properties of the dam body were obtained based both on studies of previous researchers and on experimental work done in this study. As with previous investigations, information regarding 
soil classification was obtained mainly from the study of Ono et al. [23] and Tanaka et al. [24]. However, in this study, field investigations and laboratory experiments have been conducted to extract the necessary information used for studying the dam failure. The data and discussions of dam material obtained from visual investigations and laboratory experiments are expressed.

\subsubsection{Visual investigation}

Following the dam failure, most of the upper portion of the dam was washed away; the severe damage or breach location can be observed at the maximum cross section near the left abutment from downstream. On the opposite side, the remaining dam body consisted of the compacted fill materials. The foundations of the dam were exposed to ground level on the downstream side. From visual inspection of its properties, the dam body can be classified into three parts: upper, middle, and bottom.

Photo. 1. Remaining portion of the failed dam.

Fig. 5. Soil sampling locations.

The upper layer comprises the top 6-8 $\mathrm{m}$ to the dam crest. Unfortunately, most of the upper layer was flushed away when the dam failed. However, on the left abutment, a portion of the upper embankment remains. Visual observation was performed on this section, which revealed that the fill material consists mainly of coarse sand of light color varying from light brown to gray (Photo. 1).

The middle portion is about 7-9 $\mathrm{m}$ thick. This layer can be seen clearly in the remaining portion of the dam. From visual observation of this portion, this layer appears to have been filled with brownish cohesive soil containing yellowish-gray silt, loam-type clay, and humic silty sand (Photo. 1). Moreover, traces of compacted layers can be identified, each approximately $20-30 \mathrm{~cm}$ thick.

The bottom layer is between 4 and $6 \mathrm{~m}$ thick. This portion consists mainly of layers of loam-type clay and humic silty sand ranging from black to dark gray (Photo. 1). In addition, previous investigators $[23,24]$ have indicated that some parts of the bottom layer consist mainly of dark brown sand and gravel. The black foundation material of the dam consists of organic residuals mixed with clay and silt.

\subsubsection{Laboratory experiment}

To facilitate the numerical simulation and study of the dam failure, several laboratory experiments have been performed to obtain the necessary information. Thirteen undisturbed cylinder samples were collected at the site. These samples can be defined based on their origin and testing purpose, as shown in Table 1. For each embankment layer, four samples were taken, which gave 12 samples in total for the entire dam body. As shown in Fig. 5, the soils samples were taken from locations a, b, and c, corresponding to the upper, middle, and bottom layers, respectively. These samples were tested to acquire the basic soil properties, particle size distribution, and other parameters used in the analysis. The 13th sample, taken from the middle portion, was tested to establish the coefficient of permeability. 


\subsubsection{Sieve analysis}

Sieve analysis is a practice or procedure used to assess the particle size distribution of a granular material. In this study, Due to the unavailable of the laboratory instrument at the time of study, the small particles analyses using hydrometer were not conducted and the sieve number was in the range of 4-200. However, the information on the distribution of small particles was obtained from the study of Tanaka et al. [24]. The results show that both the middle and bottom layer consist of a high percentage of fine particle sizes (Fig. 6). It can be seen that for particles that smaller than $5 \mu \mathrm{m}$, the middle and bottom soil samples are found to be about $36 \%$ and $16 \%$ respectively. Also, the clay content (particles smaller than $2 \mu \mathrm{m}$ ) of the middle and bottom portions is about $30 \%$ and $10 \%$, respectively. Whilst, the upper part is consist mainly of sandy materials. The boundaries for potentially liquefiable soil (b-b) and boundaries for most liquefiable soil (a-a) are shown in Fig. 6 [30,31]. Generally, to judge the liquefiability of soil, more than one criterion is needed.

For clayey soils, Seed and Idriss [32] stated that these soils could be susceptible to liquefaction only when all of these three conditions are met: 1) the soil that contained less than $15 \%$ of $5 \mu \mathrm{m}$ and finer particles. 2) liquid limit is less than 35 and 3) water content/liquid limit is greater than 0.9. Similarly, Andrews and Martin [33] summarized that soils are susceptible to liquefaction if they contain less than $10 \%$ finer than $2 \mu \mathrm{m}$ and liquid limit less than 32 , soils are not susceptible to liquefaction if they contain greater or equal to $10 \%$ finer than $2 \mu \mathrm{m}$ and liquid limit greater or equal to 32, and further study is required for soils that meet one, but not both, of these criteria. According to the Seed and Idriss [32] criteria's first condition, both the middle and bottom parts are not met so the soils are not being vulnerable to liquefaction. Also, by considering Andrews and Martin [33], both the middle and bottom are not susceptible to liquefaction. However, the further study should be conducted in order to obtain more accurate results including liquid limit.

\subsubsection{Triaxial test}

A triaxial test is a common laboratory method applied widely for obtaining shear strength parameters for a variety of soil types under drained or undrained conditions. The type of triaxial test applied in this study was the consolidated-undrained (cu) test using cylindrical soil specimens of $50-\mathrm{mm}$ diameter and 100-mm length. The triaxial test results of the shear strength parameters-friction angle, cohesion, and other parameters - are presented in Table 2. Also, each parameter used in the analysis can be described as following. The dry and saturated unit weight defined the mass for the element located in dry and saturated areas, respectively. Permeability or hydraulic conductivity described the fluid movement through porous media. In the elastic range, the modulus of elasticity $E$ indicated the relationship between stress and strain within the elastic region, and Poisson's ratio $v$ provided information on the effect of the load in one direction in relation to the deformation in other directions. The shear strength parameters cohesion $c^{\prime}$ and friction angle $\phi$ ' were used to form the yield surface for this model. Finally, by considering slight compressibility of water, the rate of excess pore pressure was defined as $K_{w} / n$, in which $K_{w}$ is the bulk modulus of water and $n$ is the soil porosity.

The parameters of cohesion and friction angle show that the bottom and middle portions of the dam are classed as cohesive soil, but that the upper portion is classed as loose material. Furthermore, the modulus of elasticity reveals that the deeper the soil layer, the higher its modulus becomes. The top portion of the dam is shown to have a relatively smaller modulus of elasticity than normally expected for fill materials.

It is should be noted that by taking samples from the remaining of a collapsed dam represents a difficult task and raises many questions on the reliability of the representativeness of the material properties of the retrieved samples. Therefore, the analyzed results obtained using these data and the further used of this study, should be recognized and aware of this limitation. 


\section{Table 2}

\section{FE method}

\subsection{FE model}

The FE analysis was performed under plane strain conditions. The effect between the solid and fluid phase was carried out through a u-p formulation; the governing equation of motion of coupled solidfluid problem can be written as shown in Eqs. (1) and (2).

$\mathbf{L}^{\mathrm{T}} \boldsymbol{\sigma}-\rho \mathbf{b}+\rho \mathbf{u}=\mathbf{0}$

$\mathbf{m}^{\mathrm{T}} \dot{\boldsymbol{\varepsilon}}=\operatorname{div} \hat{\mathbf{v}}+\left(\frac{n}{K_{\mathrm{W}}}\right) \dot{p}$

where the total stresses $\boldsymbol{\sigma}$, the body loads $\mathbf{b}$, and the acceleration $\ddot{\mathbf{u}}$ are time dependent with the differential operator $\mathbf{L}$ given as

$\mathbf{L}^{T}=\left[\begin{array}{ccc}\partial / \partial \mathrm{x} & 0 & \partial / \partial \mathrm{y} \\ 0 & \partial / \partial \mathrm{y} & \partial / \partial \mathrm{x}\end{array}\right]$

In addition,

$\boldsymbol{\sigma}=\boldsymbol{\sigma}^{\prime}+\mathbf{m} p, \mathbf{m}=\left\{\begin{array}{lll}1 & 1 & 0\end{array}\right\}^{\mathrm{T}}$

$\hat{\mathbf{v}}=-\mathbf{k}\left(\operatorname{gradp}-\rho_{w}(\mathbf{b}-\ddot{\mathbf{u}})\right) / \rho_{w} g$

in which the relevant parameters are effective stress $\boldsymbol{\sigma}^{\prime}$, pore pressure $p$, total stress $\boldsymbol{\sigma}$, coefficient of permeability $\mathbf{k}$, density of water $\rho_{w}$, and gravitational acceleration $g$.

In this study, 956 triangular 15-noded elements with three-point Gaussian integration, a second-order polynomial interpolation for the displacements, and a first-order interpolation for the pore water pressure were used. Two dam models have been proposed for this study. The first model is a simplified version of the original shape of the Fujinuma dam's typical section and in this study the effect of the concrete frames and panels, and the interaction among them and dam is not taken into account (Fig. 7), and the latter is based on the remains of the failed dam following the site investigation (Fig. 8). The first model was used for conducting a dynamic analysis to acquire the dynamic behavior and failure mechanism. The second dam model was used to determine the dam mode shape and natural frequency, and for verification against the microtremor observations. The modal analysis was conducted using ANSYS code [34]. The foundation was modeled by extending a 10-m-thick layer $100 \mathrm{~m}$ either side of the center. The boundary conditions were restrained in the horizontal and vertical directions at the bottom of the model. For both edges, the boundary conditions were fixed only in the lateral direction and were free in the vertical direction. To avoid the effects of wave reflection on the boundary, an absorbent boundary was applied at both ends and at the bottom of 
the boundary. The dam's body was classified into three portions: upper, middle, and bottom. The Young modulus is assumed to be constant in any of the three portions of the dam. In this study, for the dynamic analysis, the dam was analyzed under the maximum reservoir condition. The effect of reservoir pressure on the upstream face was applied as static pressure acting on the upstream slope in a direction perpendicular to the upstream face. To acquire the initial stress condition, the static and seepage analyses were conducted in advance. Dynamic analysis was performed using the Plaxis FE code [25].

Fig. 7. Original dam model.

Fig. 8. Remaining dam model.

\subsection{Material properties}

In fact, the soil behavior is non-linear and to accurately reproduce the stress-strain relationship during dynamic load, it required the advanced constitutive law along with the finite element formulation at large deformation. As it is a preliminary study, the simple elastic-perfectly plastic model was applied and later when the nonlinear finite element code has been implemented by the authors, the further study will be conducted and compared with current results. The behavior of the dam materials is described using the Mohr-Coulomb soil model, which is an elastic-perfectly plastic model with a yield surface whose elastic behavior is defined by isotropic elasticity through a linear Young's modulus $E$ and Poisson ratio v. In this study, the representative modulus of elasticity was applied using the initial stiffness of the actual soil's stress-strain curve obtained from the triaxial test. Actually, the smaller value of the primarily modulus of elasticity at larger strain can be selected however as the samples have been taken from the failed dam that might encountered the degradation of the modulus so the initial stiffness was applied in this study. The model has yield surfaces defined by cohesion $c$ and friction angle $\phi$. The generalization of the Coulomb friction failure law is then defined by

$\tau=c-\sigma_{n} \tan \phi$

in which $\tau$ is the magnitude of the shearing stress, $\sigma_{n}$ is the normal stress, $c$ is cohesion, and $\phi$ is the angle of internal friction. The Mohr-Coulomb failure surface is often expressed in terms of the invariants $p, q$, and $r$ as follows

$$
[(1 / \sqrt{3}) \sin (\theta+\pi / 3)-(1 / 3) \tan \phi \cos (\theta+\pi / 3)] q-p \tan \phi=c
$$

where 
The plastic flow rule used in this study was carried out using the associate flow rule in which the dilatancy angle is exactly the same value as the friction angle, such that the same surface is applied for the normalized plastic rule.

The cyclic soil behavior of the simple elastic-perfectly plastic is illustrated in Fig.9. It can be seen that for stress states that fall within the yield surface, the behavior is purely elastic and all strains are reversible as showed at point A-B in Fig. 9. Thereafter, if the system was loaded further until it reached or exceeded the yield surface, the plastic strain or irreversible strain is occurred as defined as point B-C in Fig. 9. At this stage, the total strain is a combination between elastic and plastic strain which is defined as point $\mathrm{C}$ in Fig. 9. And if the system is unloaded, the elastic strain is then reduced and finally vanished, left only plastic strain when the system is at rest condition (Fig. 9 C-D). Similarly, when reloaded the system, the behavior is repeated from A-D in Fig .9 as mentioned earlier.

Fig. 9. The cyclic soil behavior using the simple elastic-perfectly plastic constitutive law

In dynamic analysis, this model produced elastic behavior without the hysteretic damping. In order to include the soil's damping characteristics, the Rayleigh damping is applied therefore. Biggs [35] suggested that for geological materials, the minimum critical damping ratio commonly falls in the range of $2 \%$ to $5 \%$. Also, many researchers [36-38] conducted the dynamic analyses of an earth dam and applied the damping ratios of about 5\% to 6\%. Also, by using Mohr-Coulomb which is included the plasticity model, when the failure surface is reached the energy is subsequently dissipated though plastic deformation. Therefore, Rayleigh damping was assumed in the dynamic analysis by considering 5\% damping in the frequency range of 1.64-2.45 Hz. However, by using the simple constitutive model Mohr-Coulomb, it must be noted that the complex dynamic soil behavior cannot be captured comprehensively particularly the strain dependent behavior of stiffness and damping cannot be modeled.

The parameters of the dam material were obtained mainly from the laboratory experiments, as mentioned earlier in relation to Table 2, whereas the properties of the foundation were assumed. Each parameter used in the analysis was described earlier as stated in section 2.3.2.2.

\section{Results and discussions}

\subsection{Modal analysis}

Modal analysis is conducted to extract the natural frequency and its corresponding mode shape. In this study, two dam models were analyzed. Both cases were analyzed under the empty reservoir condition. In Fig. 10, the results of the modal analysis are shown. The natural frequency is 1.64 and $2.45 \mathrm{~Hz}$ for the first two modes, respectively. For the remaining dam model, the natural frequency is $2.35 \mathrm{~Hz}$ for the translational mode in the horizontal direction. 
Fig. 11 shows the amplification ratio that was taken from the top of the remaining dam to two locations near the dam base of the upstream and downstream slopes, defined as $2 / 1$ and $2 / 3$, respectively. By comparing the numerical results with microtremor test results, it can be seen that in the latitudinal direction, the amplification ratio is within the range of 2-5 Hz. The results obtained from the modal analysis of the remaining dam agree well with field observations in relation to the vibration in the latitudinal direction. Therefore, the estimated predominant frequencies of the original dam are 1.64 and $2.45 \mathrm{~Hz}$. The comparison between the natural frequency of the remains dam obtained from the microtremor observation and the modal analysis of the original dam model shows that the natural frequency of the actual dam model is less than the microtremor test. This is due to the geometry of the original dam which the dam's height is higher while the remains dam is plump in shape. It should be noted also that as the soils possibly subject to the large strain at the time of the dam failure that may cause degraded values of the shear modulus. As a result, the natural frequency of both microtremor test of the remains dam and the modal analysis result of the actual dam model may be different from the current results if the actual material properties can be acquired.

Fig. 10. Natural frequency. (a) $1^{\text {st }}$ mode: $1.64 \mathrm{~Hz}$ (horizontal direction). (b) $2^{\text {nd }}$ mode: $2.45 \mathrm{~Hz}$ (vertical direction).

Fig. 11. Amplification ratio.

\subsection{Dynamic analysis}

A dynamic analysis is performed to establish the possible behavior of the dam during an earthquake. The results were expressed through acceleration, deformation, shear strain, and tension crack.

\subsubsection{Acceleration}

Results show that larger maximum crest acceleration can be obtained using inverse phase of the observed and simulated motions. Therefore, the acceleration contours at the time when the maximum acceleration reached the dam crest are shown in Figs. 12 and 13 for inverse phase of the observed and simulated motions, respectively. By using the observed motion, the maximum crest acceleration is determined to be $7.42 \mathrm{~m} / \mathrm{s}^{2}$ and $8.56 \mathrm{~m} / \mathrm{s}^{2}$ accelerating towards the upstream direction at the time of $104.45 \mathrm{~s}$ and $111.60 \mathrm{~s}$ for normal and inverse phase motion (Fig. 12), respectively. For the simulated earthquake, the maximum crest acceleration is $7.60 \mathrm{~m} / \mathrm{s}^{2}$ acting towards the upstream direction at the time of $72.78 \mathrm{~s}$. Similarly, for its inverse phase, the crest experienced the maximum acceleration moving towards the upstream side with a magnitude of about $7.65 \mathrm{~m} / \mathrm{s}^{2}$ at $71.24 \mathrm{~s}$ (Fig. 13).

The observed motion contains high-amplitude waves for a longer duration than does the simulated motion. This generates a great response throughout the dam body resulting from significant inertial force acting on the dam. This causes a great amount of plastic deformation and eventually the dam failure owing to the loss of freeboard. In addition, regarding to the spectrum of the observed motion, it can be seen that this motion is characterized by a wide band. Therefore, it might possible induced resonance in the dam and caused a higher response. In contrast, the simulated motion contains highamplitude waves only for a comparatively short period; thus, this does not contribute a sufficient effect to cause large movement and settlement of the dam. 
For both motions, it can be seen that the acceleration at the dam crest is amplified significantly. The maximum amplification ratio taken from the crest to the base is 1.76 and 1.79 for the observed and simulated motions, respectively. To verify the effects of the phase of ground motion, the opposite waveforms were used as input motions and amplification ratios of 2.03 and 1.80 were obtained for the observed and simulated ground motions, respectively. This indicates that the response is very sensitive to input ground motion.

Fig. 12. Acceleration contours (inverse phase of observed motion).

Fig. 13. Acceleration contours (inverse phase of simulated motion).

\subsubsection{Deformation}

Deformation can be used for the evaluation of the safety of the dam due to freeboard loss. The results are expressed through its deformed shape and the displacement curve with respect to time at various heights along the dam centerline.

Fig. 14 shows the deformed mesh at $104.19 \mathrm{~s}$ and its corresponding displacement curves when subjected to the observed motion. It can be seen that the entire dam body was moved in the downstream direction. As time increases, plastic deformations were accumulated. This caused the permanent horizontal displacement Ux of $2.95 \mathrm{~m}$, and crest settlement Uy reached $1.80 \mathrm{~m}$ at $104.19 \mathrm{~s}$; this is considered as the point of dam failure due to the loss of freeboard. Settlements at other observation points yield a similar tendency, but the settlements were less with decreasing dam height.

In addition, the deformed meshes and deformation curves in both directions, at the end of the shaking using the inverse phase of the observed and simulated ground motion, are shown in Figs. 15 and 16. These indicate that both horizontal and vertical displacements fluctuated during the earthquake and settled continuously at a rapid rate, and then remained constant until the end of the excitation. The permanent horizontal displacement of the dam was $3.40 \mathrm{~m}$ (upstream side), $0.30 \mathrm{~m}$, and $0.42 \mathrm{~m}$ for the inverse phase of the observed, simulated, and inverse phase of simulated motion, respectively. The vertical displacement at the dam crest reached $2.90 \mathrm{~m}, 0.63 \mathrm{~m}$, and $0.60 \mathrm{~m}$ for the inverse phase of the observed, simulated, and inverse phase of simulated motion, respectively. As a result, by considering overtopping failure, the dam was able to withstand safely the simulated input motion except for the case of using the inverse phase of the observed motion, for which overflow is expected to occur.

According to the facts, the dam experienced overflow and subsequent breach. The one possible cause is that the significant settlement of the dam body led to the loss of freeboard. Thus, the observed motion does reflect the actual failure mechanism of the dam, whereas the simulated motion does not. However, all cases show that settlement is high, especially in the upper portion of the dam owing to its softness. For the changed phase, the observed motions show the significant effect of creating the displacement obtained from the normal and inverse phase, to be in opposite directions.

Fig. 14. Deformed mesh at $104.19 \mathrm{~s}$ using observed motion. 
Fig. 15. Deformed mesh at end of the analysis using inverse phase of observed motion.

Fig. 16. Deformed mesh at end of the analysis using simulated motion.

\subsubsection{Shear strain}

Shear strain provides information for understanding the location within the dam body that might be damaged severely during the earthquake excitation.

Shear strain contours for various times obtained using the observed motion are shown in Fig. 17. Most of the dam body experienced an insignificant rate of shear strain. It can be seen that initially, large shear strains occurred in the upper portion, especially on the upstream side. Thereafter, the occurrences of large shear strain can be observed clearly on both sides of the dam in the middle and bottom portions of the downstream slope. This excessive level of shear strain may indicate a possible cause for the dam failure. Similarly, shear strain contours obtained from the remaining motions, yield almost the same pattern as the previous motion (Figs. 18 and 19). However, the exception is when using an inverse phase of the observed motion, for which large shear strains can be seen on the upstream slope instead of on the downstream slope.

The sequence of dam failure has been reported by previous researchers. Initially, the dam experienced excessive deformation or a slide on the upper portion of the upstream slope. This, together with a subsequent large slide that occurred on the downstream face, yielded a loss of freeboard and triggered the overflow that resulted in the breaching of the dam. Most numerical results show good agreement with this scenario, except for the case of using the inverse of the observed motion, which exhibited large strain appearing mainly on the upstream slope. The simulated motions also yield good agreement, but only with a smaller value of shear strain.

Fig. 17. Shear strain contours at $40 \mathrm{~s}$ and at $104.19 \mathrm{~s}$ using observed motion.

Fig. 18. Shear strain contours at $40 \mathrm{~s}$ and at the end of motion using observed motion (inverse phase).

Fig. 19. Shear strain contours at $40 \mathrm{~s}$ and at the end of motion using simulated motion.

\subsubsection{Excess pore pressure}

The distribution of the excess pore pressure within the dam body and the records of the observation point A and B at $104.19 \mathrm{~s}$ using the observed motion are shown in Fig. 20. It can be seen that the excess pore pressure developed mostly at the downstream side. The maximum excess pore pressure was about $90 \mathrm{kPa}$ and it can be found near the dam's base close to the dam center line. Besides, the suction or the positive excess pore pressure can be found on the upstream face and within dam's body on the upstream side. It can be seen that from the time history curves of the excess pore pressure at the 
observation point $\mathrm{A}$ and $\mathrm{B}$ that the build-up pore pressure was fluctuated at the early period of the shaking and then kept constant until the end of the excitation. The maximum excess pore pressure obtained from the observation point $\mathrm{A}$ and $\mathrm{B}$ was about $48 \mathrm{kPa}$ and $18 \mathrm{kPa}$, respectively.

In case of using inversed phase of the observed motion, the distribution of the excess pore pressure shows that the build-up pore pressure was mostly concentrated on the upstream side. The maximum excess pore pressure was about $90 \mathrm{kPa}$ which can be found at the lower portion of the dam. On the other hand, on the downstream side, the excess pore pressure found to be in a range of 10-30 $\mathrm{kPa}$ and also the suction can be found at the downstream face.

For both the simulated and inversed phase of the simulated motion, the similar trends were obtained. The excess pore pressure found to be scattered within the dam body. The upstream side experienced the build-up pore pressure of about 20-40 kPa. Whilst, the downstream side gained greater values of the excess pore pressure especially at the lower portion of the dam. The maximum excess pore pressure was about $80 \mathrm{kPa}$ for both motions.

The results show that most of the dam body experienced the build-up pore pressure that was not high enough to equal the effective stress and trigger the total loss of the soil strength. However, in particular locations such as on the downstream side where the effective stress found to be small, the reduction of shear strength can be fairly high and led to significant permanent deformation on those areas. However, it must be noted that the Mohr-Coulomb model can only capture the excess pore pressure due to volumetric stress. Although, the excess pore pressure due to earthquake excitation was presented here, the actual phenomenon of cyclic mobility and liquefaction cannot be modeled and captured in this study.

Fig. 20. Excess pore pressure.

\subsubsection{Tension crack}

A tension crack is an extension fracture caused by tensile stress. Soil material normally has low tensile strength, and therefore it is possible for any small tensile stress, which might be a product of stretching deformation or positive pore pressure, to cause a tension crack in the soil structure. Besides, the materials used in this study, the middle and bottom, showed fairly high cohesion values which are prone to cracking. Therefore, this phenomenon is important and should be taken into account in this study. This crack provides information that might be useful for understanding the failure mechanism of the failed dam. The occurrence of tension cracks could initiate sliding or internal erosion of the dam structure.

In the analysis, it is possible to capture the tension crack during the shaking duration by illustrating the location in which the tensile stress does exceed the tensile strength. Fig. 21 summarizes the zone of the tension crack that occurred throughout the time of the analysis for both the observed and the simulated motion. It can be seen from both cases that the tension crack occurred similarly within the same location. This crack appeared clearly in the middle portion and at the toe for both sides. However, the tension crack on the upstream slope seems to penetrate deeper into the dam body. From this evidence, it would appear that sliding and internal erosion could be triggered, thereafter causing the failure of the dam.

Fig. 21. Tension crack zone. 


\section{Conclusions and discussions}

From the site investigation, it appears that the dam was breached at the maximum cross section owing to the huge volume of that portion. As per the visual investigation, the remaining of the failed dam, reservoir area, reservoir's rim and also their vicinities, were examined however there is no obvious evidence such as sand boils could be found to confirm the occurrence of liquefaction. Furthermore, in the middle and bottom portions, the material itself does not seem prone to liquefaction. Thus, in respect of this, the failure mechanism might be described as follows.

For the first scenario, owing to a relatively small elastic modulus of material used to construct the upper portion of the dam and the long duration of strong shaking, the fill material lost its strength. Consequently, sliding occurred in the top layer on the upstream slope or on both sides. Thereafter, the crest was displaced in a sliding pattern. The settlement is deemed to have continued in the same pattern until it reached the reservoir level, following which overtopping failure occurred.

For another possible scenario, owing to the weak upper portion and the long duration of strong shaking, cumulative permanent displacement could have expanded both sides and caused settlement in the middle, following which sliding occurred owing to instability. Of course, at some certain level, a coupled-failure phenomenon occurred, such as an overtopping-sliding failure.

The numerical simulation results obtained using the observed motion show that the dam was subjected to the high amplitude and long duration earthquake. Also, the spectrum of the earthquake motion is characterized by a wide band that possibly induced resonance in the dam. Thus, the dam experienced significant amplifications throughout the dam body and this led to the great driving inertia force. In addition, with a long duration of shaking, the build-up pore pressure was then developed within the dam's body especially in the lower portion of the downstream side. Although, the excess pore pressure was not high enough to match the effective stress and trigger the liquefaction in those particular locations, soils might experience the reduction of the shear strength at the locations where the effective stress is small. Accordingly, large shear strain can be observed initially on the top portion of the dam and later the large shear strains can be found on the downstream side. Regards to the sliding patterns that occurred in the top portion and on the downstream slope, the dam was settled and the plastic deformation was then accumulated and become large until the dam's crest reached the reservoir level. Therefore, the dam failed owing to the loss of freeboard that might later cause the breaching of the dam. Furthermore, in all cases, large shear strains were observed initially in the upper portion of the upstream slope, following which large shear strains commenced on the downstream side. These, together with tension cracks, might evidently indicate the cause of the sliding failure of the dam slope. In addition, these sliding patterns exhibit good agreement with the facts gathered from field observations.

Several other failure mechanisms could describe the failure of the Fujinuma dam, such as the effect of the interaction between the concrete face and the dam, or the interaction between the reservoir and the dam. However, these effects were not taken into account in this study.

Through this study, it can be seen that the quality of compacting material in the upper portion might be one possible reason for the dam failure, which brought about such a disaster to those who lived downstream. Thus, this study demonstrates that it is very important not only to design a dam that is capable of withstanding future quakes, but that the investigation and maintenance of existing dams are crucial for continued seismic safety. 
Although the numerical simulation results obtained in this study could describe the failure mechanism of the dam, this simulation is based on the small strain assumption. To gain insight into the failure mechanism of the soil structure, which is most likely to be within a large deformation regime, it is recommended to consider the effect of geometrical nonlinearity. Therefore, to address this suggestion, the development of the FE code for solving the problem at finite strain is recommended. Thus, the failure mechanism of the dam could be analyzed properly and results acquired that are more reliable. In addition, to describe other possible failure mechanisms, the material nonlinearity or other advanced constitutive laws and the proper fluid-structure interaction should be taken into account in future works.

\section{Acknowledgments}

The authors would like to acknowledge the contributions of the National Research Institute for Earth Science and Disaster Prevention for providing invaluable information. Special thanks are extended to Dr. Yoshiya Hata, Prof. Susumu Nakamura, and Dr. Atsushi Nozu for providing the ground motion data used in this study. The authors would like to express their very great appreciation to both Prof. Mamoru Mimura and Prof. Susumu Iai for their invaluable guidance and suggestions regarding this research work. A special note of thanks is given to the staff and technicians of the laboratory of Geodisaster Division, Disaster Prevention Research Institute, Kyoto University, Japan, for their help in handling the instruments. The authors would also like to express their very great appreciation to Dr. Suttisak Soralump from Kasetsart University for his useful and constructive suggestions and guidance during the site observation.

\section{References}

[1] M.A. Biot, General theory of three-dimensional consolidation, J. Appl. Phys, 12 (1941) 155164.

[2] M.A. Biot, Theory of propagation of elastic waves in a fluid saturated porous solid. I. low-frequency range, Journal of the Acoustical Society of America, 28(2) (1956) 168-178.

[3] F. Oka, A. Yashima, T. Shibata, M. Kato, R. Uzuoka, FEM-FDM coupled liquefaction analysis of a porous soil using an elasto-plastic model, Applied Scientific Research, 52(1994) 209-245.

[4] S. Diebels, W. Ehlers, Dynamic analysis of a fully saturated porous medium accounting for geometrical and material non-linearities, International Journal for numerical methods in Engineering, 39 (1996) 81-97.

[5] R. W. Lewis, B. A. Schrefler, The finite element method in the static and dynamic deformation and consolidation of porous media, John Wiley and Sons, New York, 1998.

[6] O.C. Zienkiewicz, A.H.C. Chan, M. Pastor, B.A. Schrefler, T. Shiomi, Computational geomechanics with special reference to earthquake engineering, John Wiley and Sons, Chichester, 1998.

[7] C. Li, R.I. Borja, R.A. Regueiro, Dynamics of porous media at finite strain, Computation Methods in Applied Mechanics and Engineering, 193 (2004) 3837-3870. 
[8] P.K. Woodward, D.V. Griffiths, Influence of viscous damping in the dynamic analysis of an earth dam using simple constitutive models, J. Computers and Geotechnics, 19(3) (1995) 245263.

[9] S.L. Kramer, Geotechnical Earthquake Engineering, The United States of America, Prentice Hall, Inc., 1996.

[10] N. Uddin, A dynamic analysis procedure for concrete-faced rockfill dams subjected to strong seismic excitation, J. Computers and Structures, 72 (1999) 409-421.

[11] M. Wieland, Seismic Aspects of Dams, Commission International Des Grands Barrages, Switzerland, 2003.

[12] L. Tancev, Dam and Appurtenant Hydraulic Structures. Taylor \& Francis, London, 2005

[13] S. Sica, L. Pagano, A. Modaressi, Influence of past loading history on the seismic response of earth dams, J. Computers and Geotechnics, 35 (2008) 61-85.

[14] S. Rampello, E. Cascone, N. Grosso, Evaluation of the seismic response of a homogeneous earth dam, J. Soil Dynamics and Earthquake Engineering, 29 (2009) 782-798.

[15] B. Charatpangoon, K. H. Park, C. Hansapinyo, P. Warnitchai, Seismic Safety Evaluation of Mea Kuang Udomthara Dam, Proceedings of the 3rd ASIA Conference on Earthquake Engineering ACEE, Bangkok, Thailand, (2010).

[16] S. Soralump, K. Tansupo, Safety analyses of Srinagarind dam induced by earthquakes using dynamic response analysis method, Proceedings of the International Conference on Performance-based Design in Earthquake Geotechnical Engineering IS-Tokyo, (2009) 987-994.

[17] H. Fallah, M. Wieland, Evaluation of Earthquake Safety of Koman Concrete Face Rockfill Dam in Albania, Proceedings of the 3rd Asian Conference on the Earthquake Engineering ACEE, Bangkok, Thailand, (2010).

[18] J. A. Bountry, T. J. Randle, Upstream impact after the 1976 failure of Teton dam, proceedings of the seventh federal interagency sedimentation conference, Reno, Nevada, (2001).

[19] U.S. Department of Interior. Bureau of Reclamation (USBR). [Online]. Available: / www.usbr.gov/pmts/sediment/projects/teton River/TetonRiver.html [accessed 03.06.12]

[20] H. B. Seed, I. M. Idriss, K. L. Lee, F. I. Makadisi, Dynamic analysis of the slide in the lower San Fernando dam during the earthquake of February 9, 1971. ASCE, Journal of Geotechnical engineering Division, GT9 (1975) 889-911.

[21] Y. Yamaguchi, T. Iwashita, S. Mitsuishi, Preliminary investigation of dams stricken by the iwate-miyagi nairiku earthquake in 2008, Proceedings of the fifth east Asian regional dam conference international symposium on co-existence of environment and dams, (2008).

[22] L. F. Harder Jr., K. I. Kelson, T. Kishida, R. Kayen, Preliminary Observations of the Fujinuma dam failure following the March 11, 2011 Tohoku Offshore Earthquake, Japan, Geotechnical reconnaissance of the 2011 Tohoku Japan Earthquake, GEER Association 25e (2011). 
[23] K. Ono, S. Kazama, S. Kawagoe, Y. Yokoo, L. Gunawardhana., Possible earthen dam failure mechanisms of Fujinuma reservoir due to the Great East Japan Earthquake of 2011, Hydrological Research Letters 5 (2011) 69-72.

[24] T. Tanaka, F. Tatsuoka, Y. Mohri, Earthquake Induced failure of Fujinuma Dam, International symposium on dams for a changing world, ICOLD, Kyoto, Japan, 6 (2012) 47-52.

[25] R. B. J. Brinkgreve, P. A. Vermeer, Plaxis ver. 7, Material models manual, Balkema, Rotterdam, 1998.

[26] Wikipedia. [Online]. Available: /http://en.wikipedia.org/wiki/Fujinuma_Dam. [accessed 07/01/12]

[27] Japan Meteorological Agency (JMA). [Online]. Available: /http://www.jma.go.jp/en/quake/ [accessed 06.07.12]

[28] National Research Institute for Earth Science and Disaster Prevention (NIED). [Online]. Available: /http://www.kyoshin.bosai.go.jp. [accessed 06.01.12]

[29] Y. Hata, S. Nakamura, A. Nozu, Seismic waveform evaluation at the Fujinuma Dam for the 2011 off the Pacific coast of Tohoku Earthquake-Application of site effect substitution method to a huge subduction earthquake, Journal of Structural Engineering, JSCE, Vol. 58A (2011) 250-263.

[30] Japan port and Harbor Association, Technical standards for port and harbor facilities in Japan, (1999) 281-288.

[31] A. Numata, S. Mori, Limits in the gradation curves of liquefiable soils, proceeding of the $13^{\text {th }}$ world conference on earthquake engineering, Vancouver, B.C., Canada, (2004) Paper No. 11.

[32] H. B. Seed, I. M. Idriss, Ground motions and soil liquefaction during earthquakes, Earthquake Engineering Research Institute, Berkeley, California, 1982.

[33] D. C. A. Andrews, G. R. Martin, Criteria for liquefaction of silty soils, Proceedings of the $12^{\text {th }}$ World Conference on Earthquake Engineering, Auckland, New Zealand, (2000).

[34] ANSYS, Inc., ANSYS Mechanical APDL Structural Analysis Guide, ver. 14.5, 2012.

[35] J. M. Biggs, Introduction to Structural Dynamics. New York, McGraw-Hill, 1964.

[36] M.T. Chen, Harichandran, Response of an earth dam to spatially varying earthquake ground motion, Journal of Engineering Mechanics, 127, No. 9, (2001) 932-939.

[37] A. Anastasiadis, N. Klimis, K. Makra, B. Margaris, On seismic behaviour of a $130 \mathrm{~m}$ high rockfill dam: an integrated approach. Proceeding of the $13^{\text {th }}$ Conference on Earthquake Engineering,Vancouver, Canada, No. 2933 (2004).

[38] D. Chakraborty, D. Choudhury, Investigation of the Behavior of Tailings Earthen Dam Under Seismic Conditions. American Journal of Engineering and Applied Sciences 2, No. 3, (2009) 559-564. 


\section{Figure captions}

Fig. 1. (a) Location of the Fujinuma dam (@2013 Google. Map data. ( ) Google. ZENRIN). (b) Sukagawa and the dam site (Map data @2013 AutoNavi. Google. SK planet. ZENRIN). (c) Fujinuma dam.

Fig. 2. Typical cross section of the main dam.

Fig. 3. Main dam layout.

Fig. 4. Input motions. (a) Observed motion at FKS017 $15 \mathrm{~km}$ from the dam site [28]. (b) Simulated motion at the dam site [29]. (c) Spectrum of observed motion. (d) Spectrum of simulated motion.

Photo. 1. Remaining portion of the failed dam.

Fig. 5. Soil sampling locations.

Fig. 6. Particle size distribution.

Fig. 7. Original dam model.

Fig. 8. Remaining dam model.

Fig. 9. The cyclic soil behavior using the simple elastic-perfectly plastic constitutive law

Fig. 10. Natural frequency. (a) $1^{\text {st }}$ mode: $1.64 \mathrm{~Hz}$ (horizontal direction). (b) $2^{\text {nd }}$ mode: $2.45 \mathrm{~Hz}$ (vertical direction).

Fig. 11. Amplification ratio.

Fig. 12. Acceleration contours (inverse phase of observed motion).

Fig. 13. Acceleration contours (inverse phase of simulated motion).

Fig. 14. Deformed mesh at $104.19 \mathrm{~s}$ using observed motion.

Fig. 15. Deformed mesh at end of the analysis using inverse phase of observed motion.

Fig. 16. Deformed mesh at end of the analysis using simulated motion.

Fig. 17. Shear strain contours at $40 \mathrm{~s}$ and at $104.19 \mathrm{~s}$ using observed motion.

Fig. 18. Shear strain contours at $40 \mathrm{~s}$ and at the end of motion using observed motion (inverse phase).

Fig. 19. Shear strain contours at $40 \mathrm{~s}$ and at the end of motion using simulated motion.

Fig. 20. Excess pore pressure. 
Fig. 21. Tension crack zone. 


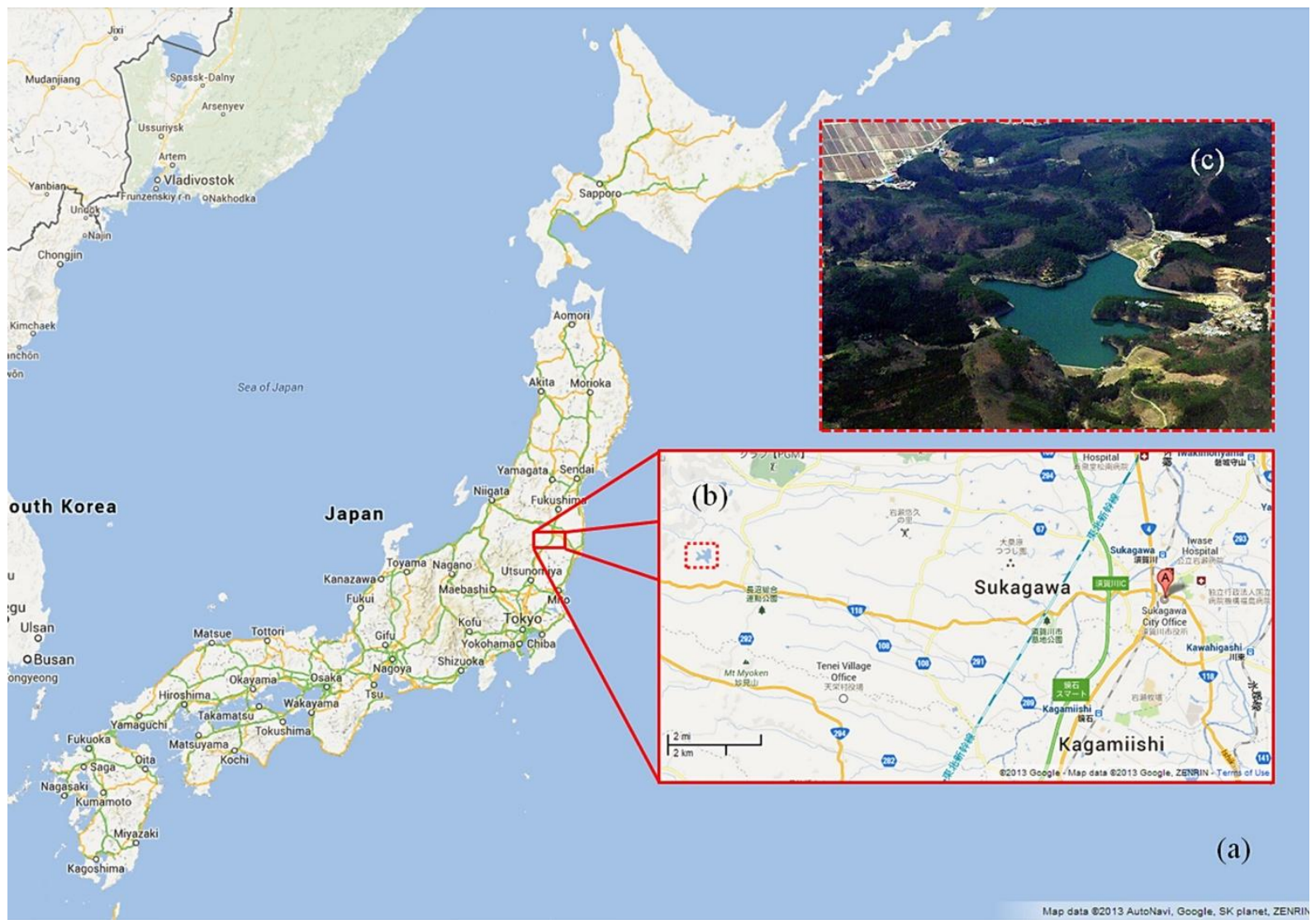

Fig1

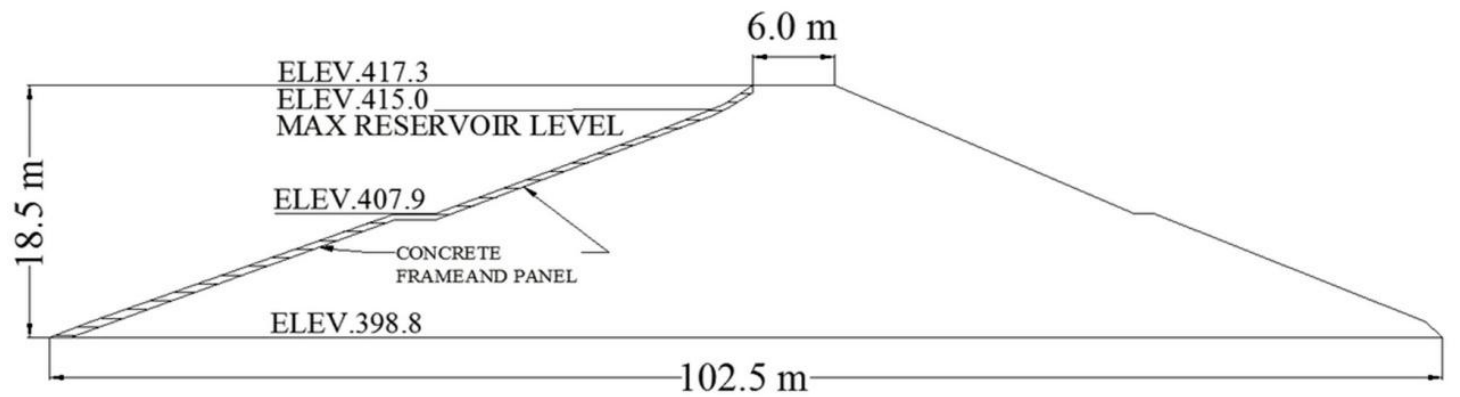

Fig2

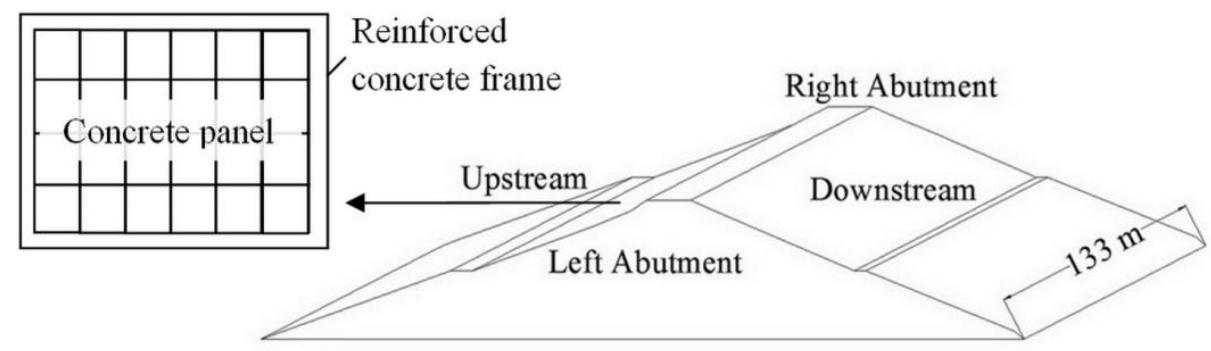

Fig3 

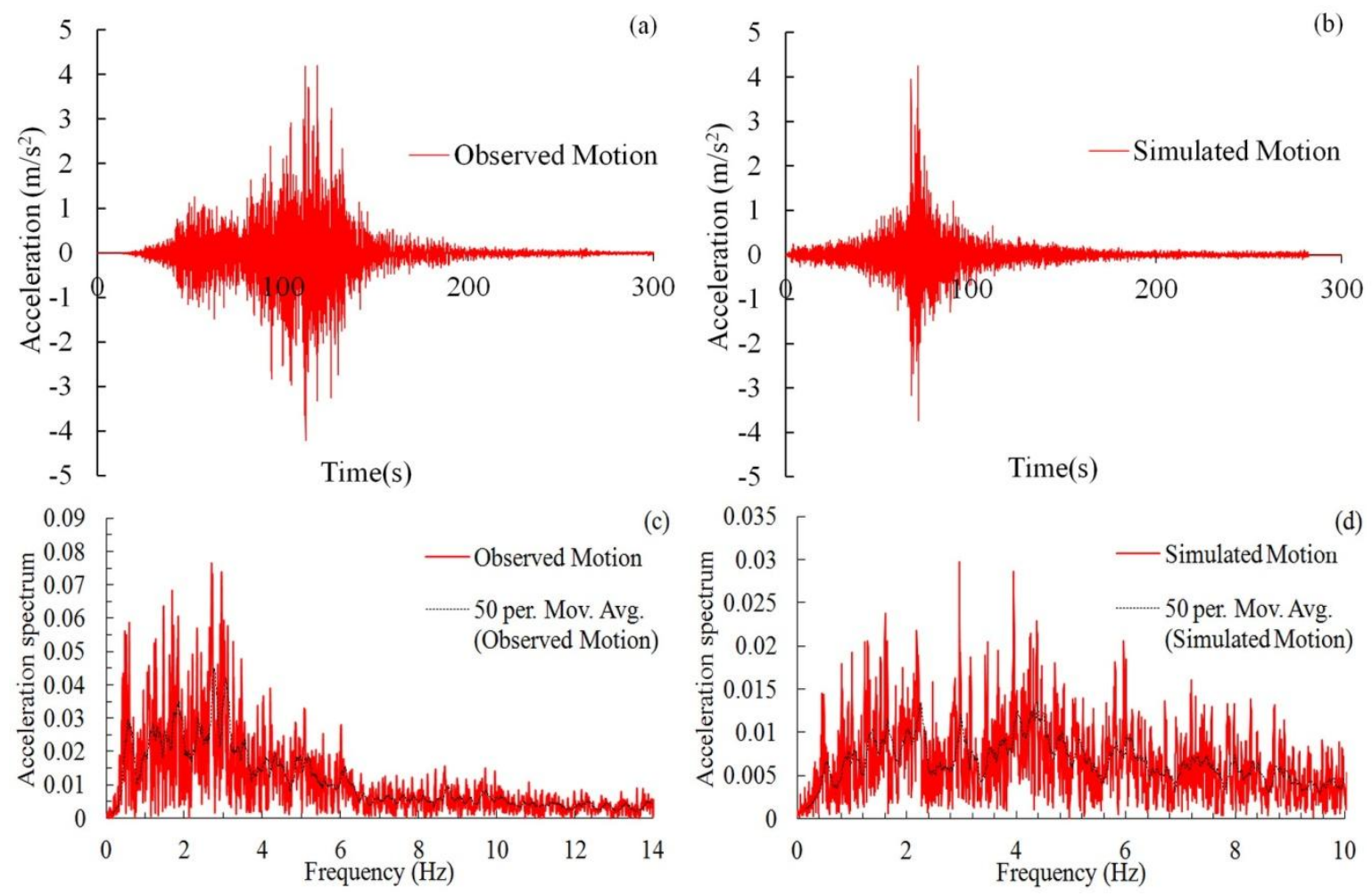

Fig4 (a),(b),(c) and (d)

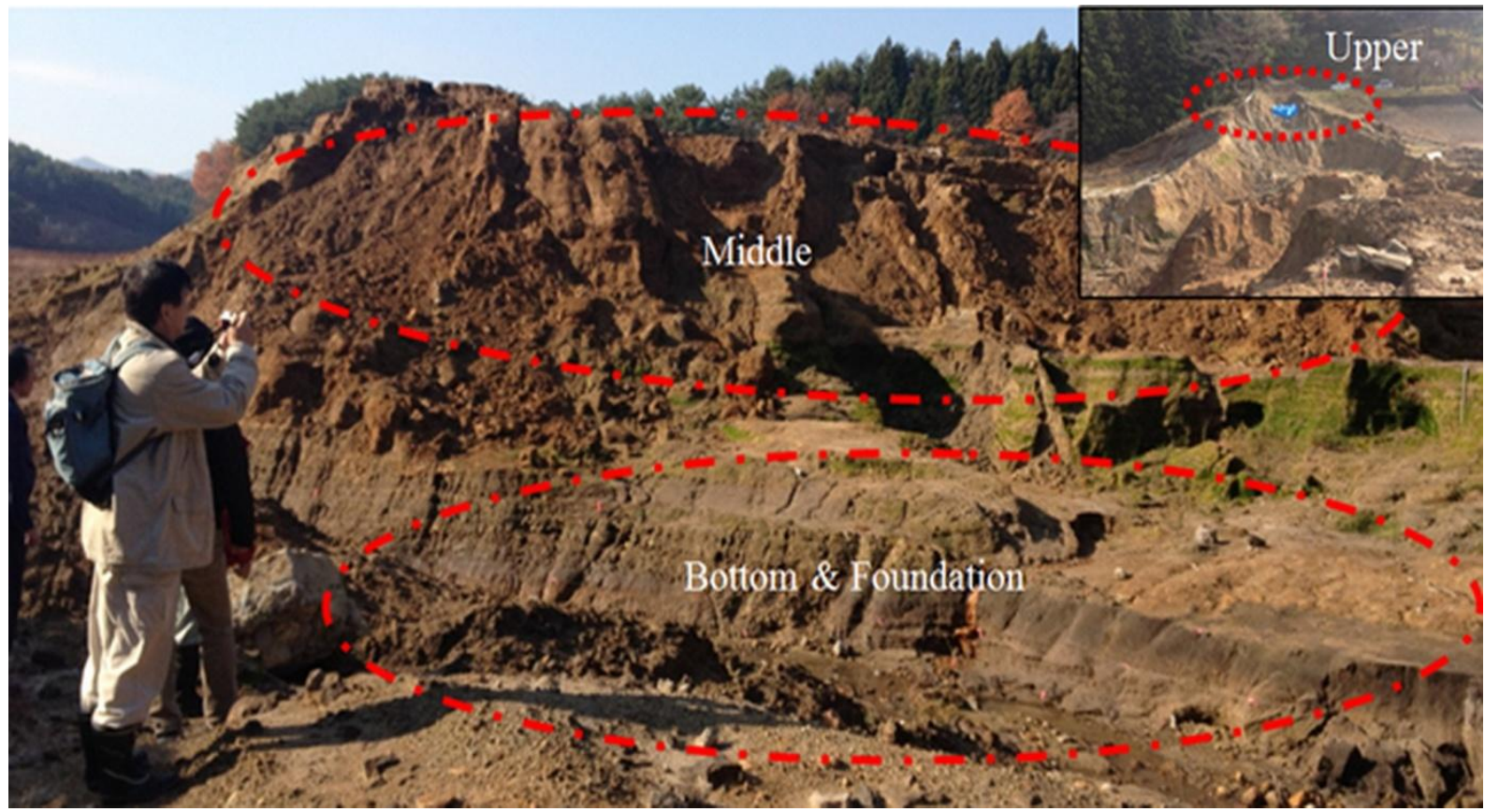

Photo1 


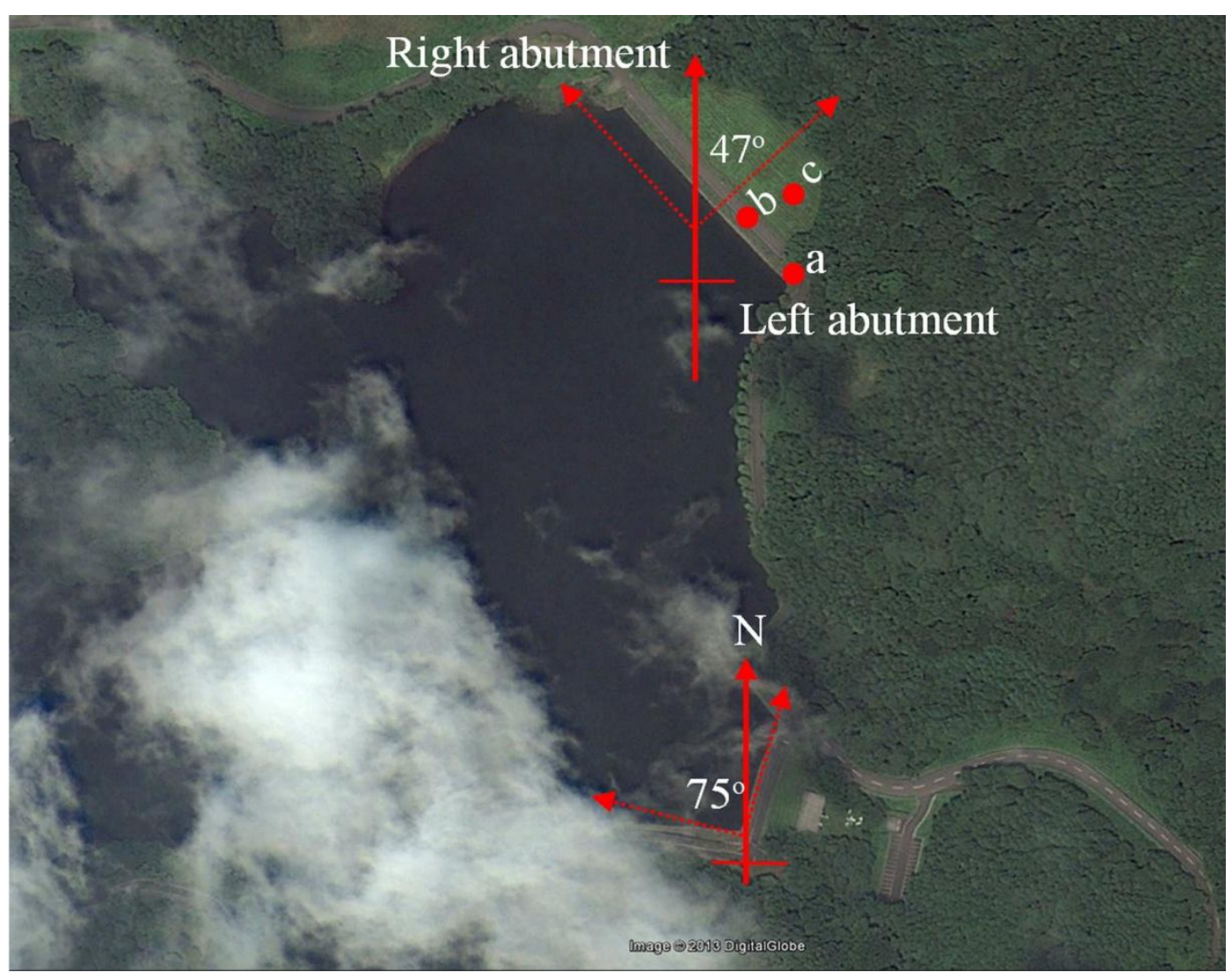

Fig5

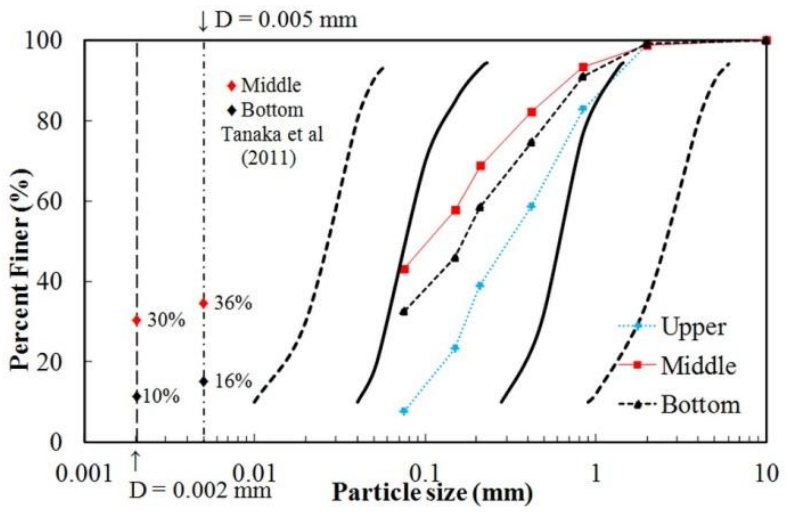

Fig6 


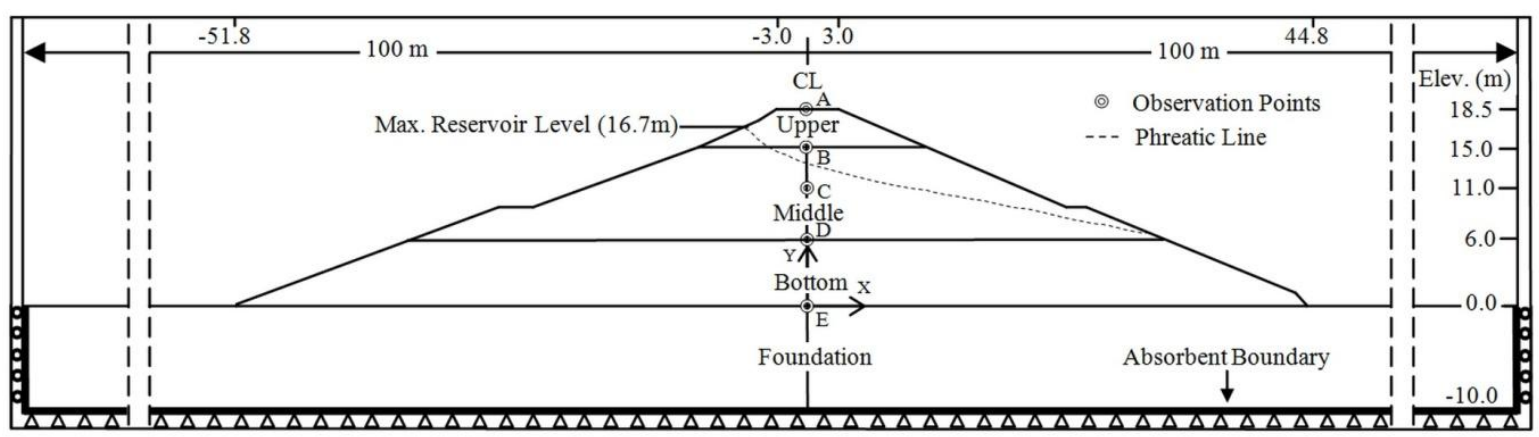

Fig7

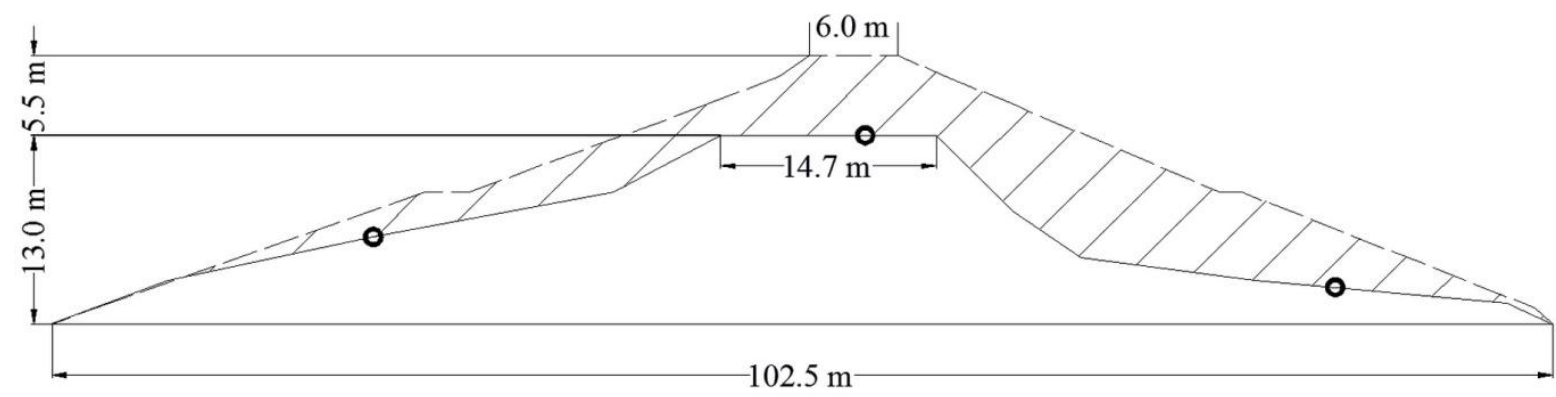

Fig8

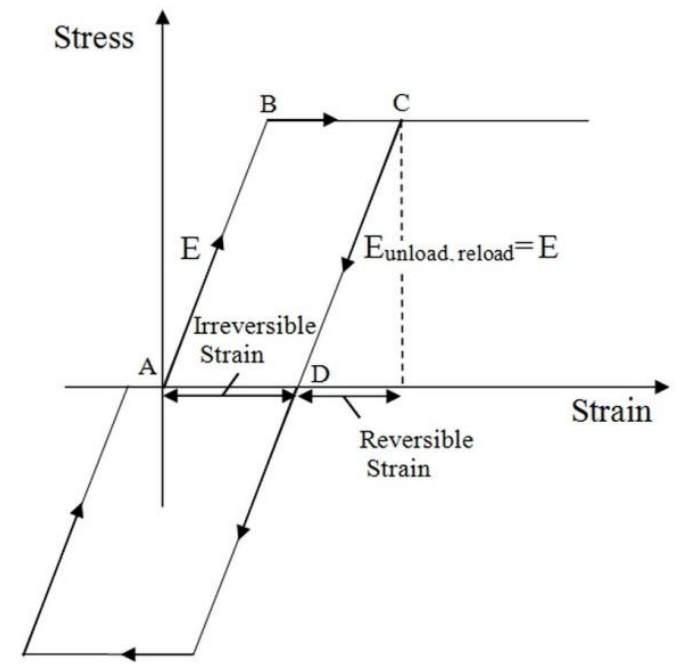

Fig9 


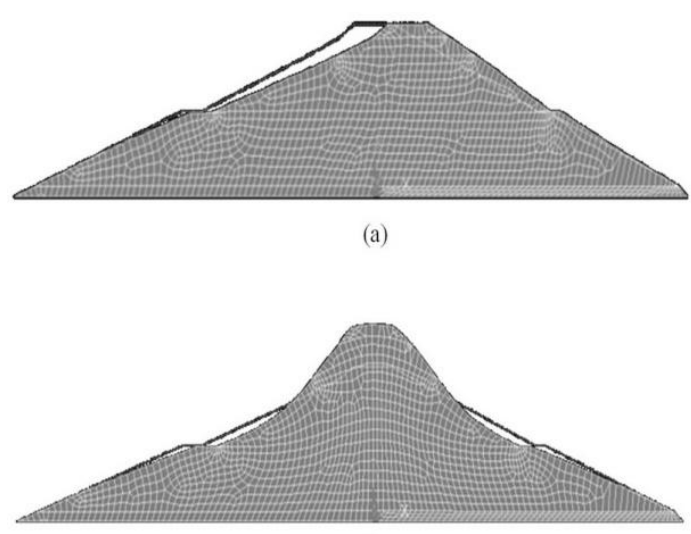

(b)

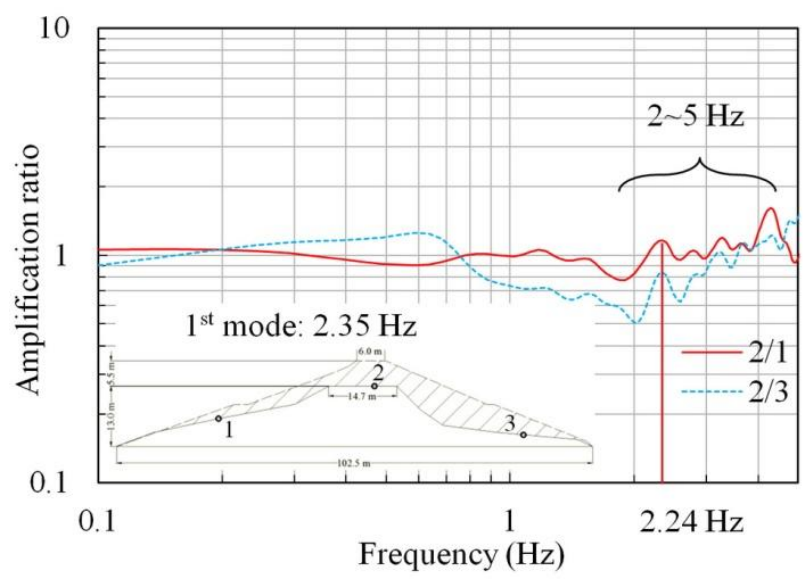

Fig11

Fig10

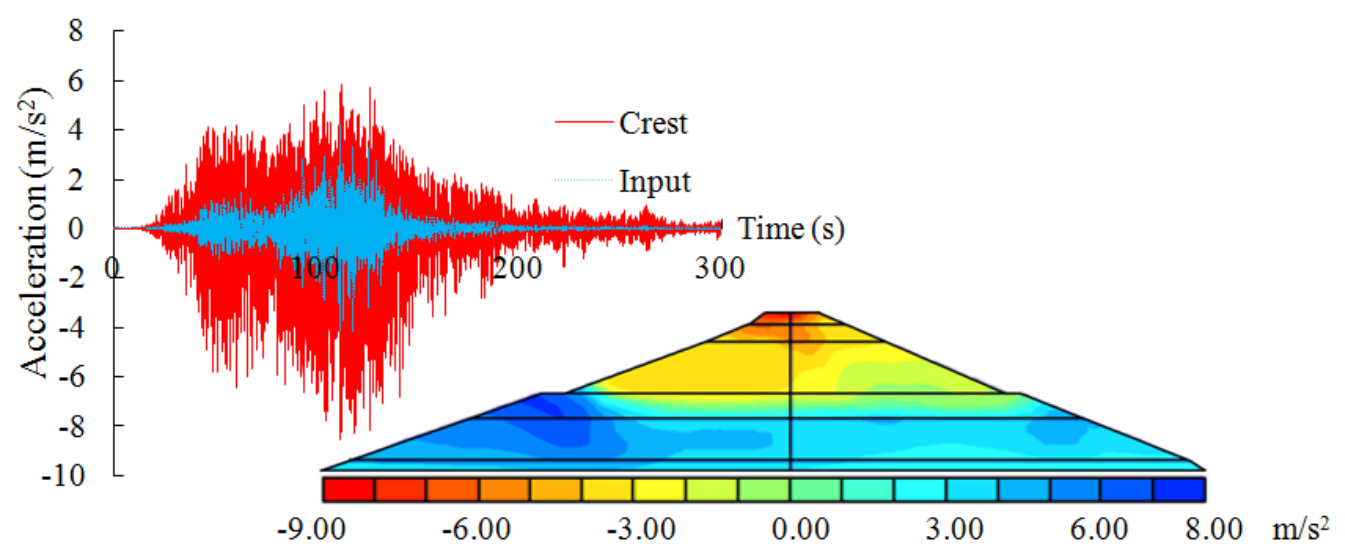

Fig 12

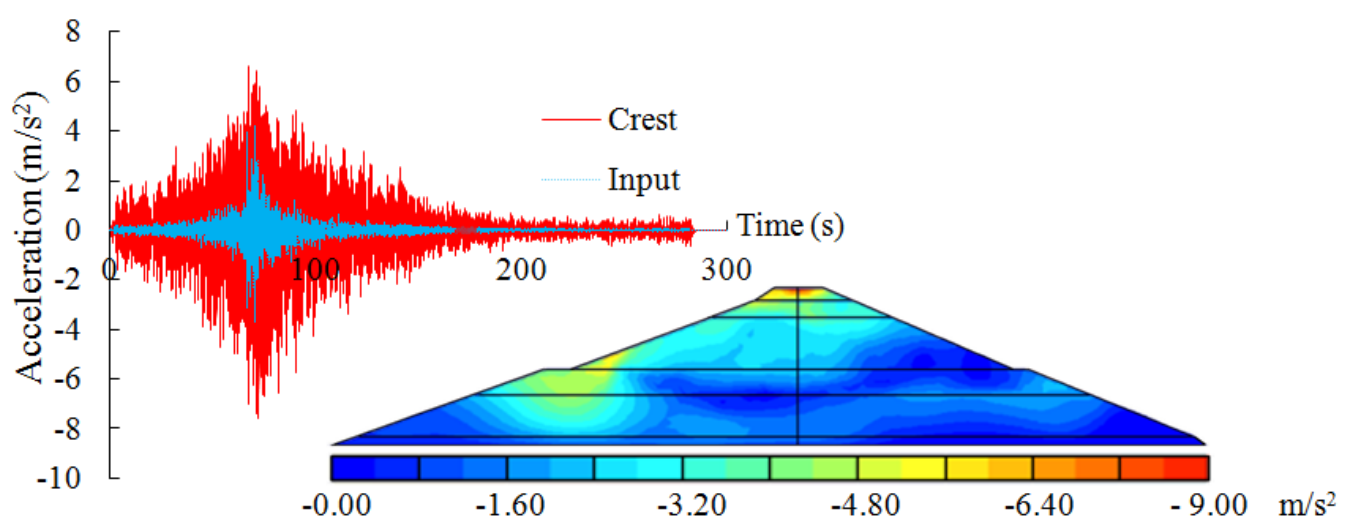

Fig13 


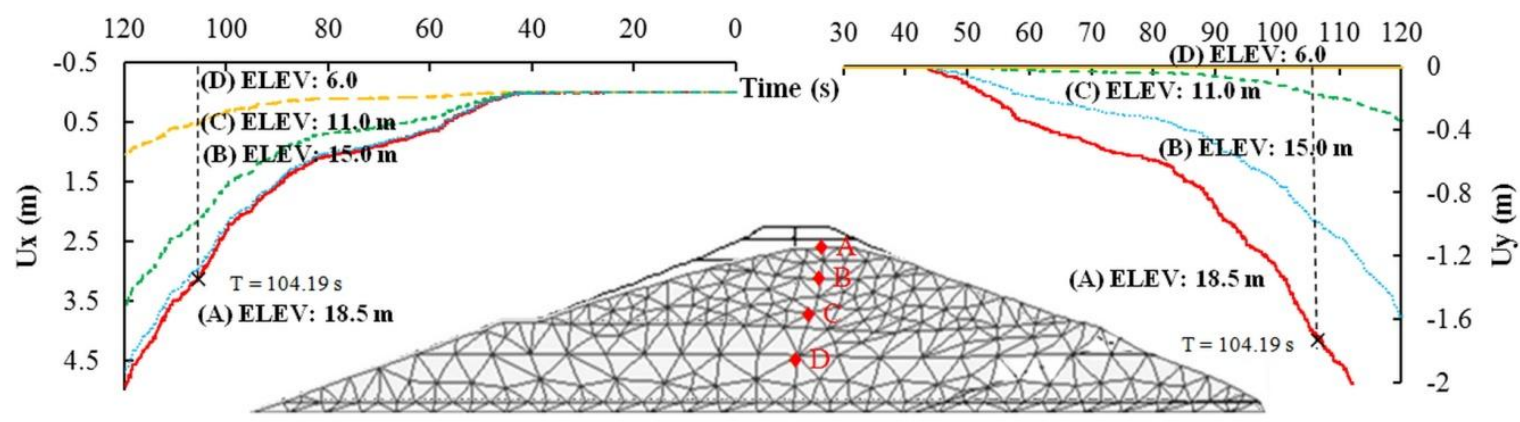

Fig 14

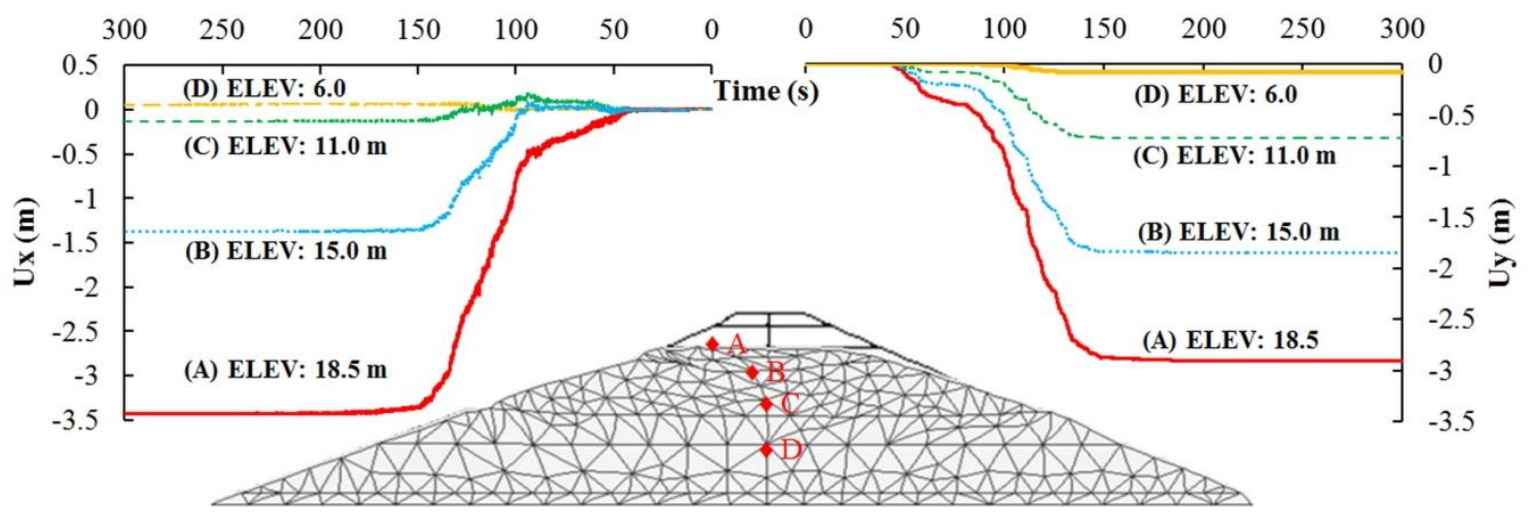

Fig 15

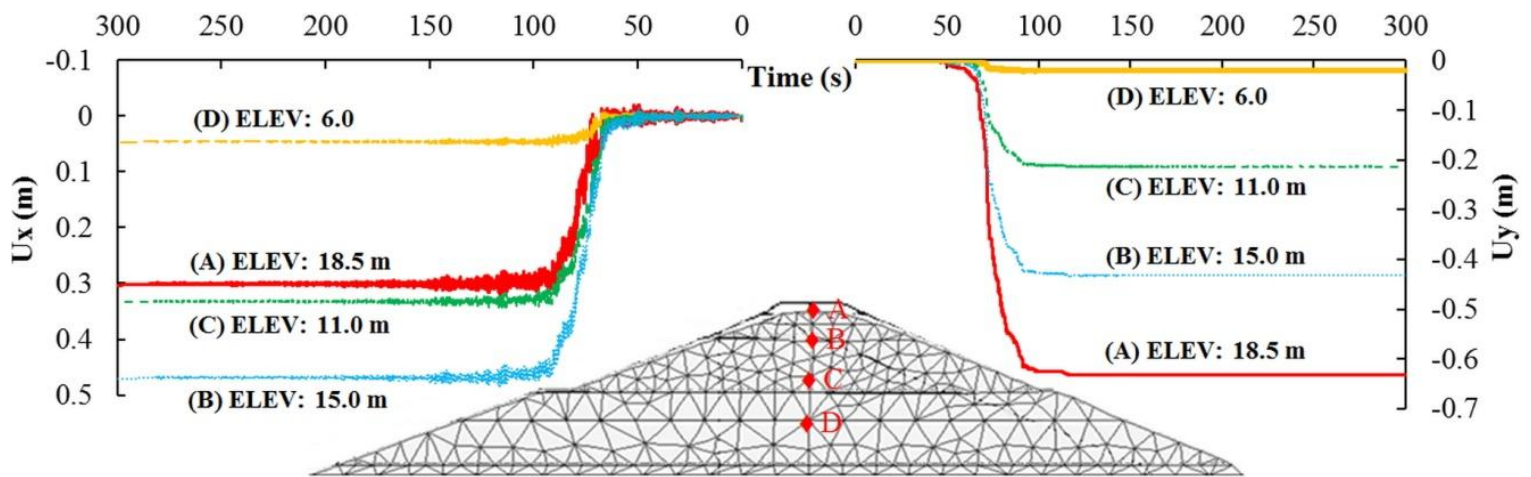

Fig 16
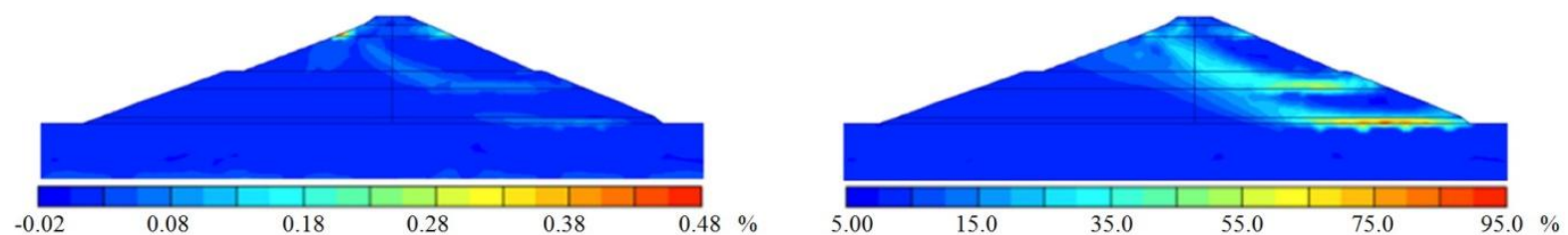

Fig 17 

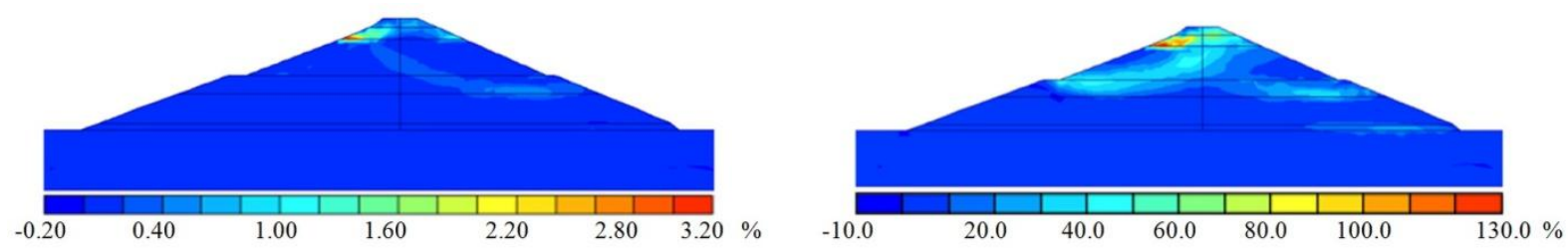

Fig 18
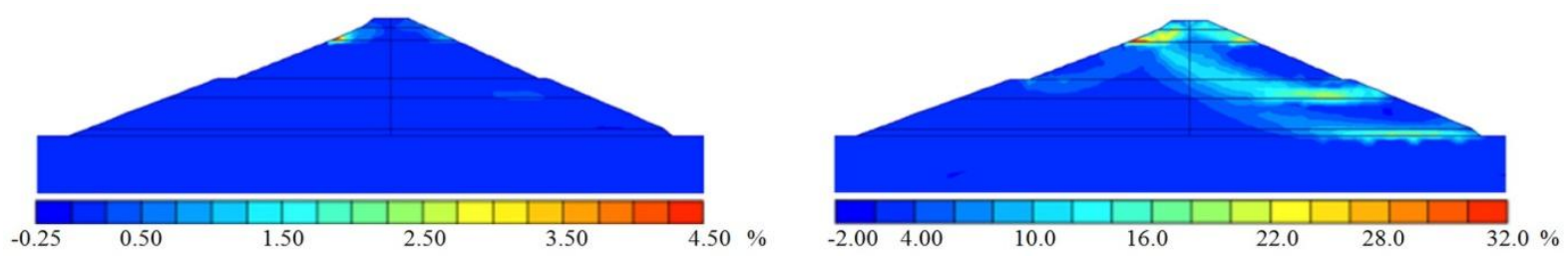

Fig 19

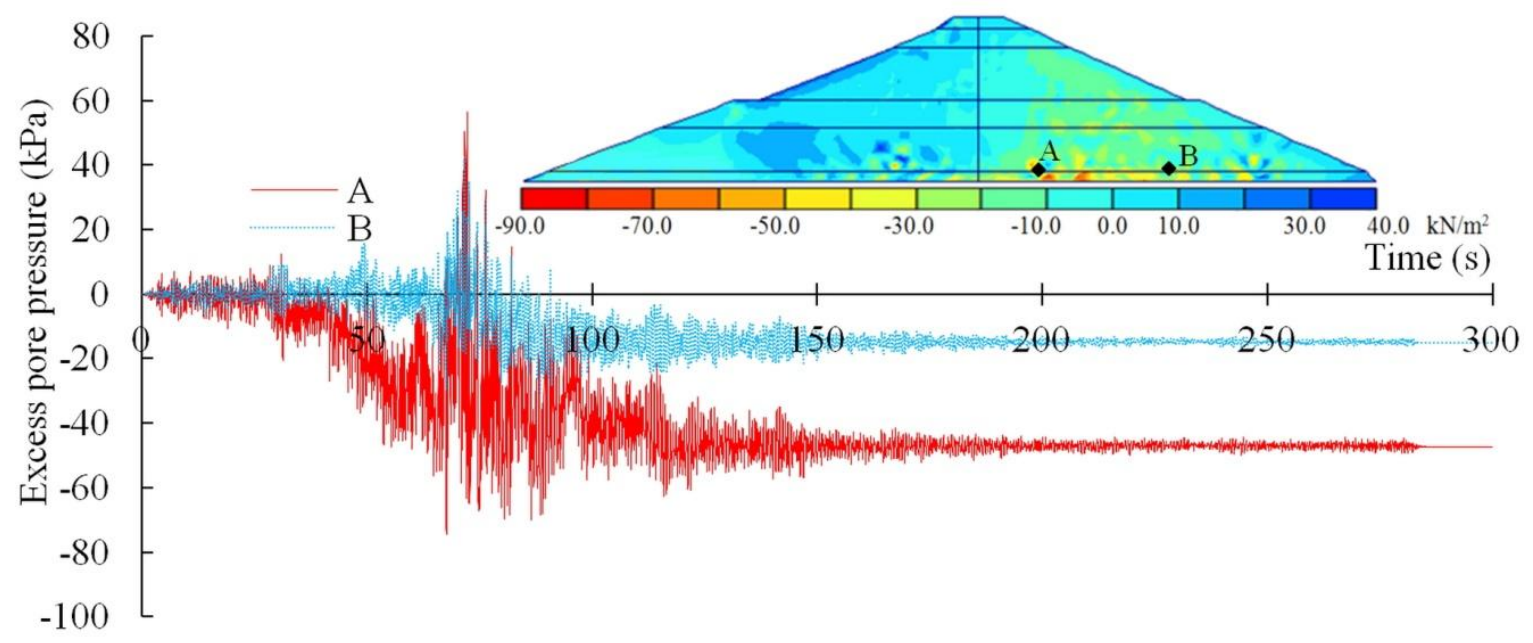

Fig20

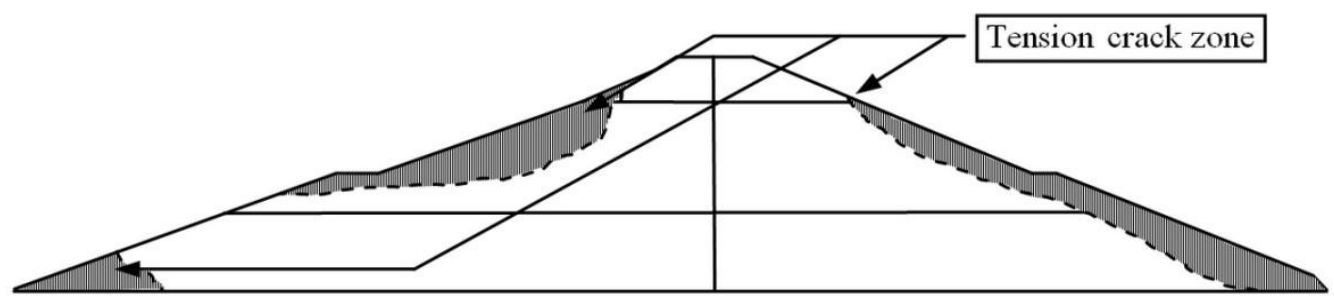

Fig21 
Table 1

Soil samples

\begin{tabular}{cc}
\hline Type of Testing & $\begin{array}{c}\text { Number of } \\
\text { samples }\end{array}$ \\
\hline Permeability test & 1 \\
Triaxial CU test & 12 \\
- $\quad$ Bottom layer & 4 \\
• Middle layer & 4 \\
• Upper layer & 4 \\
\hline Total & $\mathbf{1 3}$ \\
\hline
\end{tabular}

Table 2

Soil properties

\begin{tabular}{|c|c|c|c|c|c|c|c|c|c|}
\hline Materials & Layer & $\begin{array}{c}\gamma_{d r y} \\
\left(\mathbf{k N} / \mathbf{m}^{3}\right)\end{array}$ & $\begin{array}{c}\gamma_{\text {sat }} \\
\left(\mathbf{k N} / \mathbf{m}^{3}\right)\end{array}$ & $\begin{array}{c}k_{y} \cong k_{x} / 4 \\
(\mathrm{~m} / \mathrm{s})\end{array}$ & $\begin{array}{c}E \\
(\mathbf{M P a}) \\
\end{array}$ & $\begin{array}{l}K_{w} / n \\
(\mathbf{G P a})\end{array}$ & $v$ & $\begin{array}{c}c^{\prime} \\
(\mathbf{k P a})\end{array}$ & $\begin{array}{c}\phi^{\prime} \\
\text { deg }\end{array}$ \\
\hline \multirow[t]{3}{*}{ Dam body } & Bottom & 16.0 & 18.00 & $5.5 \mathrm{E}-7$ & 50.0 & 1.87 & 0.3 & 18.4 & 31 \\
\hline & Middle & 14.0 & 16.00 & $5.5 \mathrm{E}-7$ & 30.0 & 1.12 & 0.3 & 7.80 & 32 \\
\hline & Upper & 16.0 & 18.00 & $5.5 \mathrm{E}-7$ & 17.5 & 0.65 & 0.3 & 0.0 & 37 \\
\hline Foundation & - & 30.0 & - & - & 300 & - & 0.2 & - & - \\
\hline
\end{tabular}

